\title{
RESPON PERTUMBUHAN DAN PRODUKSI TANAMAN KAILAN (BRASSICA OLERACEA VAR ACHEPALA)TERHADAP KONSENTRASI PUPUK ORGANIK CAIR DAN MEDIA TANAM PADA PERTAMAN HIDROPONIK
}

\author{
RESPONSE TO THE GROWTH AND PRODUCTION OF KAILAN PLANT \\ (BRASSICA OLERACEA VAR ACHEPALA) TO THE CONCENTRATION OF \\ LIQUID ORGANIC FERTILIZER AND PLANTING MEDIA IN HYDROPONIC \\ PLANTS
}

\author{
Rosmadelina Purba ${ }^{1)}$ Jonner Purba ${ }^{2)}$ Andre Joy Hezwkiel Tampubolon ${ }^{3)}$ \\ ${ }^{1,2,3)}$ Fakultas Pertanian Program Studi Agroteknologi Universitas Simalungun \\ rosmadelinapurba@usi.ac.id jonnerpurba@gmail.com
}

\begin{abstract}
ABSTRAK : Penelitian ini berjudul" Respon Pertumbuhan dan Produksi Tanaman Kailan (Brassica oleracea var achapala) Terhadap Konsentrasi Pupuk Organik Cair Dan Media Tanam Pada Pertanaman Hidroponik" .Penelitianini dilaksanakanBulan Oktober hingga November ,di rumah kasa Fakultas Pertanian USI dengan ketiggian \pm 400 mdpl.

Tujuan penelitian adalah untukmengetahuirespon pertumbuhan dan produksi tanaman kailan (Brassica oleracea var achapala) terhadap konsentrasi pupuk organik cair dan media tanam pada pertanaman hidroponik.Penelitiaanmenggunakan rancangan acaklengkap(RAL)faktorial, dengan2faktorperlakuan,dimanafaktorpertamaadalahkonsentrasi pupuk organik cair yangterdiridari 3 tarafyaitu $\mathrm{N}_{1}=5 \mathrm{ml} / 1, \mathrm{~N}_{2}=15 \mathrm{ml} / 1, \mathrm{~N}_{3}=25 \mathrm{ml} / 1$, sedangkanuntukfaktorkeduaadalahmedia tanamterdiri dari 3tarafyaitu $\mathrm{M}_{1}=$ Rockwool, $\mathrm{M}_{2}=$ Arang Sekam, $\mathrm{M}_{3}=$ Cocopeat. Parameter yang diamati dalam penelitian ini diantaranya: tinggi tanaman, jumlah daun, berat akar,berat segar tanaman

Hasil penelitianmenunjukkanbahwaperlakuanKombinasi perlakuan konsentrasi pupuk organik cair dan media tanam berpengaruh nyata terhadap tinggi tanaman pada umur 28 HST tetapi ,tidak berpengaruh nyata terhadap tinggi tanaman umur 14 dan $21 \mathrm{HST}$, jumlah daun umur 14,21,28 HST , Berat akar, Berat segar per tanaman Perlakuan (N3M2 ) menunjukan tinggi tanaman tertinggi pada umur $28 \mathrm{HST}(29,04 \mathrm{~cm})$. Jumlah daun umur 28 HST tertinggi terdapat pada perlakuan $\mathrm{N}_{3} \mathrm{M}_{3}, \mathrm{~N}_{3} \mathrm{M}_{2}$ yang menunjukkan rata-rata yang sama $(9,58)$. Berat akar $\mathrm{N}_{3} \mathrm{M}_{3}(3,55 \mathrm{~g})$ Berat segar tanaman tertinggi pada perlakuan $\mathrm{N}_{3} \mathrm{M}_{3}$ dan $\mathrm{N}_{3} \mathrm{M}_{2}$ Masing-masing 11,75 g.
\end{abstract}

Kata Kunci: Kaylan,Pupuk organic cair, Media Tanam

ABSTRACT : This study entitled "The Response to Growth and Production of Kailan (Brassica oleracea var achapala) Against the Concentration of Liquid Organic Fertilizer and Planting Media in Hydroponic Planting". This research was conducted from October to November, at the screen house of the USI Faculty of Agriculture with a height of \pm 400 masl.

The research objective was to determine the response of growth and production of kailan (Brassica oleracea var achapala) to the concentration of liquid organic fertilizers and planting media on hydroponic cultivation. The research used a factorial completely randomized design $(C R D)$, with 2 treatment factors, where the first factor was the concentration of liquid organic fertilizer consisting of 3 levels, namely $N 1=5 \mathrm{ml} / l, N 2=15 \mathrm{ml} / l, N 3=25 \mathrm{ml} / \mathrm{l}$, while for the second factor, the planting medium consists of 3 levels, namely $M 1=$ Rockwool, $M 2=H u s k$ Charcoal, M3 = Cocopeat.The parameters observed in this study included: plant height, number of leaves, root weight, plant fresh weight. 
The results showed that the combination of concentration of liquid organic fertilizer and planting media had a significant effect on plant height at the age of 28 DAS but, did not significantly affect plant height at 14 and 21 DAS, number of leaves aged 14, 21, 28 DAS, root weight, and fresh weight per plant. (N3M2) shows the highest plant height at the age of 28 DAS $(29.04 \mathrm{~cm})$. The highest number of leaves aged 28 DAS was found in the N3M3 and N3M2 treatments which showed the same average $(9,58)$. N3M3 root weight $(3.55 \mathrm{~g})$ The highest plant fresh weight in N3M3 and N3M2 treatments was $11.75 \mathrm{~g}$, respectively.

Key words: Kaylan, Liquid Organic Fertili

\section{A. PENDAhuluan}

\section{Latar Belakang}

Kailan (Brassica oleraceae var achepala) merupakan sayuran yang termasuk kedalam jenis kubis-kubisan (Brassicaceae) yang berasal dari negeri China. Beberapa keistimewaan yang menyebabkan banyaknya permintaan akan sayuran ini bagian tanaman yang dikonsumsi yaitu bagian batang dan daun yang empuk renyah dan agak manis. Kandungan gizi kaylan sangat baik untuk kesehatan, dalam 100 gram bahan mentah mengandung vitamin A, Vitamin B1, lemak ,calcium, zat besi magnesium dan pospor. Kaylan mengandung 7540 IU vitamin A, $115 \mathrm{mg}$ vitamin C, dan $62 \mathrm{mg} \mathrm{Ca}, 2,2 \mathrm{mg}$ Fe. (Annisava, 2013). Permintaan kaylan cukup besar yakni 92 ton /tahun ,sementara jawa barat hanya mampu menyediakan 20 ton /tahun(BPS Jabar (2014) dalam (Andhika \& Sugiono, 2017). Untuk mencapai kondisi masyarakat yang hidup sehat dan sejahtera di masa yang akan datang, dan dalam rangka meningkatkan swasembada pangan dan seruan ketahanan pangan terutama bagi masyarakat yang tidak memiliki lahan yang luas, maka hidroponik merupakan pilihan yang tepat. Hidroponik merupakansolusi di bidang pertanian dengan menggunakan teknologi sederhana untuk memudahkan masyarakat dalam bercocok tanam. Hidroponik mampu menghasilkan produksi tanaman yang lebih terjamin kebebasannya dari hama penyakit yang berasal dari tanah, dapat dijadikan profesi baru sebagai mata pencaharian bagi petani dan masyarakat yang tidak memiliki pekerjaan, meningkatkan pemenuhan sumber gizi keluarga dan masyarakat, dan apabila diusahakan dalam skala besar dapat meningkatkan ekspor produksi hortikultura segar dan berkualitas tinggi sehingga dapat menambah devisa negara(Numan Travis dan Omaye (2015)Dalam (Sidiq Fadhil, 2019)Hidroponik merupakan suatu budidaya tanaman dengan menggunakan media non tanah sebagai tempat tumbuh tanaman dengan pemenuhan nutrisi pada tanaman. Hal tersebut dilakukan karena fungsi tanah sebagai pendukung akar tanaman dan perantara larutan nutrisi dapat digantikan dengan mengalirkan atau menambah nutrisi, air dan oksigen melalui media tersebut (Roidah, 2014). Hidroponik mempunyai kelebihan diantaranya adalah produksi per tanaman lebih besar dan kualitas lebih baik, kehilangan pasca panen lebih minimum, harga lebih tinggi dan relatif konstan, kepadatan tanaman per satuan luas dapat dilipat gandakan sehingga menghemat penggunaan lahan, mutu produk (bentuk, ukuran, rasa, warna kebersihan) lebih terjamin, tidak tergantung musim atau waktu tanam, dan panen dapat sesuai dengan kebutuhan pasar(Agustina, 2019)

(Perwtasari et al., 2012)menyatakanPenyerapan nutrisi tanaman dipengaruhi oleh media tanam. Media tanam merupakan tempat akar tanaman menyerap unsur-unsur hara yang dibutuhkan oleh tanaman. Media tanam yang baik merupakan media yang dapat mendukung pertumbuhan dan kehidupan tanaman. Penunjang keberhasilan dari sistem budidaya hiroponik adalah media yang bersifat porus dan aerasi baik serta nutrisi yang tercukupi untuk pertumbuhan tanaman. Prihmantoro dan Indriani (2005)dalam(A.Wahyuningsih, Anis, Sisca Fajriani, 2016) menjelaskan bahwa untuk budidaya hidroponik media arang sekam relatif murah, mempunyai porositas yang baik, tetapi media arang sekam hanya dapat digunakan sebanyak dua kali periode tanam, sedangkan pasir dapat digunakan berulang kali setelah dibersihkan lagi, tetapi kekurangan dari media pasir adalah berat dan porositas kurang dibandingkan dengan arang sekam. 
Hal yang perlu diperhatikan dalam pengembangan teknologi hidroponik adalah pemberian nutrisi atau pemupukan.Pupuk organik cair dapat dijadikan sebagai salah satu alternatif sumber larutan nutrisi. Pupuk organic cair adalah larutan yang membawa satu atau lebih unsur yang dibutuhkan tanaman dan mudah larut .Kelebihan pupuk organic cair adalah pada kemampuannya memberi unsur hara sesuai dengan kebutuhan tanaman.Salah satu fungsi pupuk organic cair adalah mendorong meningkatkan pembentukan klorofil daun sehingga meningkatkan fotosintesa tanaman dan pembentukan Nitrogen dari udara.(Wahyu et al., 2019)). Pemberian POC dengan dosis 100\% dan interval waktu 4 hari sekali mampu meningkatkan serapan nitrogen tanaman sawi sebesar $23,80 \%$ dibandingkan dengan perlakuan lainnya. Pengaplikasian POC untuk tanah berpasir dapat mningkatkan jumlah daun 18,75\%, Produksi berat basah 55,84\% ,produksi berat kering 53,09\% (Samadi, 2017)

\section{Tujuan Penelitian}

a) Untuk mengetahui respon pertumbuhan dan produksitanaman kailan(Brassica oleracea var achepala)terhadap konsentrasi pupuk organik cair pada pertanaman hidroponik.

b) Untuk mengetahui respon pertumbuhan dan produksitanaman kailan (Brassica oleracea var achepala)terhadap media tanam pada pertanaman hidroponik.

c) Untuk mengetahui respon pertumbuhan dan produksitanaman kailan(Brassica oleracea var achepala)terhadap konsentrasi pupuk organik cair dan media tanam pada pertanaman hidroponik.

\section{Hipotesis Penelitian}

a) Ada respon pertumbuhan dan produksi tanaman kailan (Brassica oleracea var achepala) terhadap konsentrasi POC pada pertanaman hidroponik.

b) Ada respon pertumbuhan dan produksi tanaman kailan(Brassica oleracea var achepala) terhadap media tanam pada pertanaman hidroponik.

c) Ada responpertumbuhan dan produksi tanaman kailan(Brassica oleracea var achepala)terhadap konsentrasi POC dan media tanam pada pertanaman hidroponik.

\section{Kegunaan Penelitian}

Dapat menjadi bahan informasi bagi pihak yang membutuhkan .

\section{B. METODE PENELITIAN}

Penelitian ini dilaksanakan bulan Oktober sampai dengan November2020, di Rumah Kasa Universitas Simalungun,dengan ketinggian tempat \pm 400 mdpl.Bahan yang digunakan adalah benih kailan Full White 921,pupuk AB mix,pupuk organik cair, kain flanel, rockwool, arang sekam, cocopeat, netpot, baki hidroponik,dan air.Alat yang digunakan adalah tray penyemaian, gergaji, pisau, pinset,gunting,gelas ukur,TDS meter,timbangan analitik, alat penyemprot dan alatalat lain yang diperlukan saat penelitian. Penelitian ini menggunakan Rancangan Acak Lengkap (RAL) Faktorial dengan dua Faktor. Faktor pertama terdiri dariKonsentrasi Pupuk Organik Cair terdiri dari 3 taraf yaitu :N $1=5 \mathrm{ml} / \mathrm{l}$ air , $\mathrm{N} 2=10 \mathrm{ml} / \mathrm{l}$ air,N $3=15 \mathrm{ml} / \mathrm{l}$ air.Faktor kedua yaitu : Media tanam hidroponik terdiri dari 3 taraf yaitu ;M1 = Rockwool, M2 = Arang Sekam, M3 = Cocopeat.Kombinasi perlakuan sebanyak 9 kombinasi.Jumlah ualangan 3 , Jumlah Baki Hidroponik $=27$ Baki,Luas Baki Hidroponik $=41 \mathrm{~cm} \times 31 \mathrm{~cm}$ x $13 \mathrm{~cm}$,Jarak antar tanaman $=36 \mathrm{~cm}$ x $26 \mathrm{~cm}$.Data yang diperoleh dianalisis secara statistik dan dilanjutkan dengan uji Beba Nyata Terkecil (BNT) pada tarag 5\%. 
Parameter yang diamati, Tinggi tanamanumur 14 HST,21 HST,28 HST, Jumlah daun 14 HST, 21 HST,28 HST , Berat akar, Produksi segar.

\section{HASIL DAN PEMBAHASAN}

\section{Tinggi Tanaman $(\mathbf{c m})$}

Hasil Uji Beda Rata-rata tinggi tanaman umur 14 ,21,28 HST, Jumlah Daun umur 14,21,28 HST, Berat Akar , Produksi Segar, akibat perlakuan konsentrasi POC dan Media Tanam pada pertanaman Hidroponik dapat dilihat pada tabel 1.

Tabel 1:Uji Beda Rata-rata tinggi tanaman umur $14,21,28$ HST, Jumlah Daun umur 14,21,28 HST, Berat Akar , Produksi Segar, akibat perlakuan konsentrasi POC dan Media Tanam pada pertanaman Hidroponik

\begin{tabular}{|c|l|l|l|l|l|l|l|c|}
\hline Perlakuan & \multicolumn{4}{|l}{ Tinggi Tanaman } & \multicolumn{3}{l|}{ Jumlah Daun } & Berat \\
Akar & $\begin{array}{l}\text { Produksi } \\
\text { Segar/Tana } \\
\text { man }\end{array}$ \\
\hline & 14 & 21 & 28 & 14 & 21 & 28 & & 13,72 \\
\hline N1 & 15.22 & 21.75 & 26.33 & 6.42 & 7.88 & $8.88 \mathrm{~b}$ & 2,82 & 12,61 \\
\hline N2 & 15.89 & 22.68 & 26.29 & 6.31 & 8.00 & $8.86 \mathrm{~b}$ & 2,79 & 14,14 \\
\hline N3 & 14.91 & 22.11 & 27.28 & 6.44 & 7.82 & $9.56 \mathrm{a}$ & $2,73 \mathrm{a}$ & 12,21 \\
\hline M1 & 15.43 & 22.11 & 26.50 & 6.50 & 7.89 & 9.28 & $2.22 \mathrm{~b}$ & 13,89 \\
\hline M2 & 15.15 & 22.44 & 26.79 & 6.33 & 7.86 & 8.94 & $2.65 \mathrm{~b}$ & 14,38 \\
\hline M3 & 15.44 & 21.99 & 26.61 & 6.33 & 7.92 & 9.06 & $3.53 \mathrm{a}$ & 12,54 \\
\hline N1M1 & 14.73 & 21.21 & $25.92 \mathrm{bc}$ & 6.58 & 7.83 & 9.17 & 2.63 & 13,71 \\
\hline N1M2 & 14.63 & 22.04 & $26.08 \mathrm{bc}$ & 6.25 & 7.50 & 8.58 & 2.50 & 14,92 \\
\hline N1M3 & 16.31 & 22.00 & $27.00 \mathrm{~b}$ & 6.42 & 8.00 & 8.83 & 3.54 & 11.33 \\
\hline N2M1 & 16.50 & 23.54 & $27.71 \mathrm{ab}$ & 6.33 & 7.92 & 9.08 & 2.04 & 13,58 \\
\hline N2M2 & 15.75 & 22.00 & $25.25 \mathrm{c}$ & 6.25 & 8.08 & 8.67 & 2.83 & 12,92 \\
\hline N2M3 & 15.42 & 22.50 & $25.92 \mathrm{bc}$ & 6.33 & 8.00 & 8.83 & 3.50 & 12,75 \\
\hline N3M1 & 15.04 & 21.58 & $25.88 \mathrm{bc}$ & 6.58 & 7.92 & 9.58 & 2.00 & 14,38 \\
\hline N3M2 & 15.08 & 23.29 & $29.04 \mathrm{a}$ & 6.50 & 8.00 & 9.58 & 2.63 & 13,29 \\
\hline N3M3 & 14.60 & 21.46 & $26.92 \mathrm{~b}$ & 6.25 & 7.75 & 9.50 & 3.55 & \\
\hline
\end{tabular}

Keterangan: Angka yang diikuti oleh notasi yang tidak sama pada kolom yang sama berbeda nyata pada taraf $5 \%$

Tabel 1 menunjukkan Kombinasi perlakuan konsentrasi pupuk organik cair dan media tanam (N3M2) $15 \mathrm{ml} /$ liter air dan media arang sekam pada umur 28 HST menunjukkan tinggi tanaman tertinggi $(29,04)$,yang tidak berbeda nyata dengan perlakuan lainnya. Hal ini disebabkan karena Semakin tinggi konsentrasi pupuk yang diberikan sampai batas optimum maka semakin baik pertumbuhan tanaman. Kandungan usur hara yang ada pada pupuk organik cair belum memadai untuk memacu pertumbuhan tanaman. Tanaman Kaylan memerlukan unsur hara yang cukup bagi pertumbuhan dan produksi tanaman.. Salah satu unsur yang sangat dibutuhkan adalah Nitrogen untuk meningkatkan pertumbuhan vegetatif sehingga daun menjadi lebih lebar dan berwarna Hijau (Wahyudi,2010 dalam(Sopandie, 2014)

Indah(2006)dalam (Knaofmone, 2016)pemberian pupuk organik cair dengan konsentrasi 3 $\mathrm{ml} / \mathrm{l}$ air meningkatkan parameter pertumbuhan dan hasil yang paling optimum.Media tanam juga merupakan factor yang menentukan pertumbuhan dan produksi tanaman. Menurut (Fiona, 2010)Penambahan arang sekam padamedia tumbuh memberikan pengaruh nyataterhadap pertumbuhan tinggi semai jabon.Penambahan arang sekam dapat meningkatkanpertumbuhan tinggi 
semai jabon sebesar18,31\% - 28,36\%.Pengaruh Media tanam dan dosis pupuk organik cair terhadap tinggi tanaman dapat dilihat pada gambar 1.

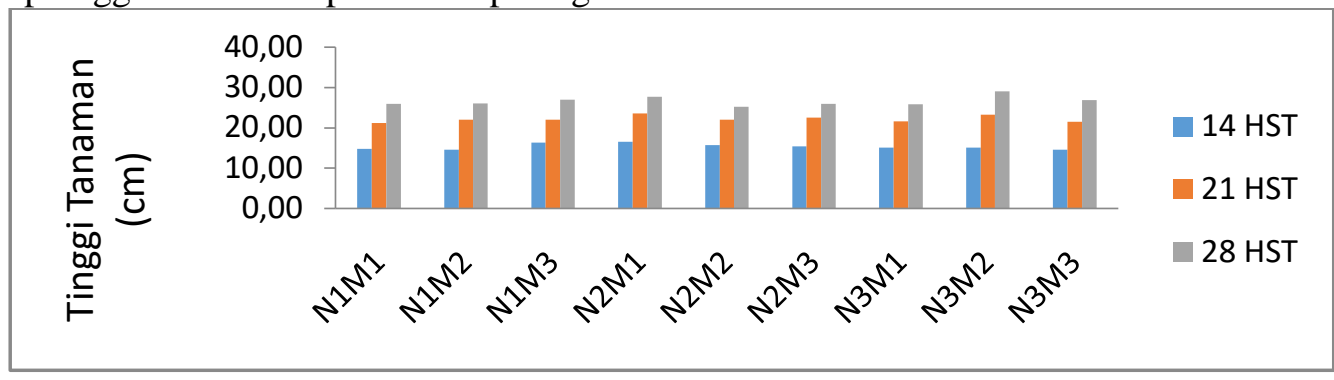

Gambar 1. Histogram Interaksi Pupuk Organik Cair dan Media Tanam Terhadap Tinggi Tanaman.

\section{Jumlah Daun (helai)}

Tabel 1menunjukkan pada umur 28 HST kombinasi perlakuan N3 M1 dan N3M2 ,menghasilkan jumlah daun terbanyak masing masing $(9,58)$ yang tidak berbeda nyata dengan yang lainnya. Hal ini disebabkan karena Semakin tinggi konsentrasi pupuk yang diberikan sampai batas optimum maka semakin baik pertumbuhan tanaman.Menurut Indah(2006)dalam (Knaofmone, 2016)Pemberian pupuk organik cair dengan konsentrasi $3 \mathrm{ml} / \mathrm{l}$ air pada tanaman cabe berpengaruh secara nyata terhadap beberapa parameter pertumbuhan dan hasil tanaman. Menurut Lakitan dalam(Iskandar, 2016).Agar tanaman tumbuh sempurna maka sebaiknya semua unsur hara esensial harus tersedia dalam jumlah yang cukup bagi tanaman.

Menurut hasil penelitia(Fiona, 2010)Penambahan arang sekam dapat meningkatkanpertumbuhan tinggi semai jabon sebesar18,31\% - 28,36\%.Pengaruh pupuk organic cair dan media tanam terhadap jumlah daun dapat dilihat pada gambar 2.

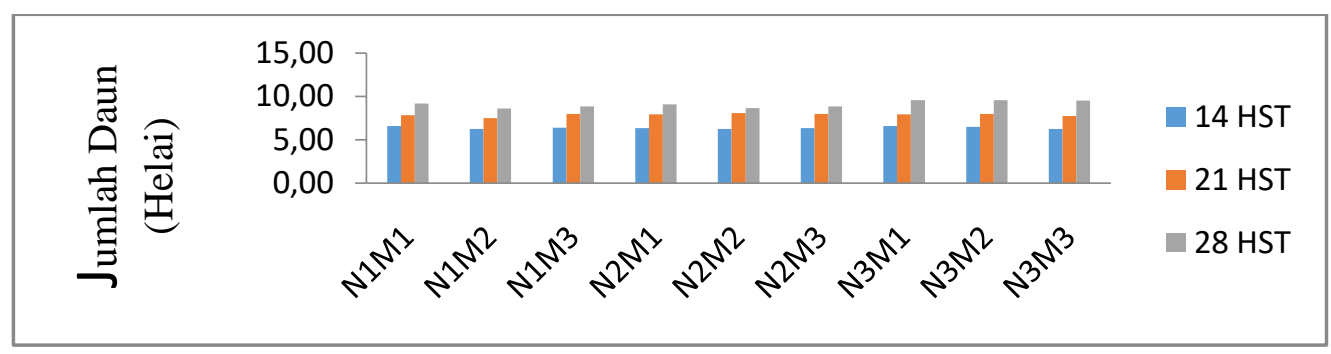

Gambar 6. Histogram interaksi konsentrasi pupuk organik cair dan media tanam terhadap jumlah daun.

\section{Berat Akar (gr)}

Pada tabel 1 diperoleh perlakuan kombinasi N3M3 $(3,55)$ menghasilkan rata - rata berat akar tertinggi yang tidak berbeda nyata dengan perlakuan lainnya. Hal ini diduga karena pupuk organik cair yang digunakan memiliki kadar Nitrogen yang rendahsehingga pertumbuhan akarpun lambat.Aziz, et al (2006)dalam(Sopandie, 2014) bahwa penambahan nitrogen yang cukup akan mempercepat laju pembelahan dan pemanjangan sel,pertumbuhan akar,batang,dan daun berlangsung dengan cepat.Media tanam Cocopeat memiliki porositas yang lebih baik yang memberikan sirkulasi udara yang baik (aerasi) bagi pertumbuhan akar. Menurut Susilo dan Koesnawaty,2004 dalam(Andhika \& Sugiono, 2017)) Media arang sekam memiliki kelebihan dalam hal kemampuan membawa air dan aerasi yang baik sehingga mampu memberi hasil yang lebih baik bagi tanaman.Pengaruh Pupuk Organikmcair dan Media terhadap berat akar tertera pada gambar 3. 


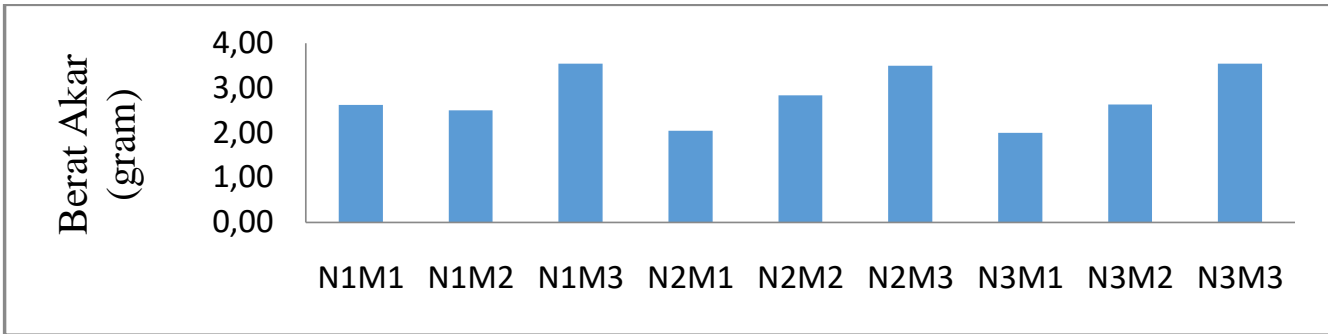

Gambar 3. Histogram Interaksi Perlakuan Konsentrasi Pupuk Organik Cair dan Media Tanam terhadap Berat Akar.

\section{Produksi Segar Per Tanaman (g)}

Tabel 1 menunjukkan bahwa Perlakuan kombinasi yaitu N1M3 menghasilkan produksi bersih per tanaman tertinggi (14,92) yang tidak berbeda nyata dengan perlakuan lainnya.Hal ini diduga karena semakin tinggi dosis pupuk yang diberikan semakin banyak kandungan unsur hara yang tersedia sehingga produksi meningkat.Wibisono dan Basri (1993) dalam (Dede Haryadi, Husna Yetti, 2015),menyatakan bahwa tanaman dapat tumbuh dan berproduksi dengan sempurna bila unsur hara yang diperlukan mencukupi. Penggunaan media tanam berpengaruh terhadap tinggi tanaman, jumlah daun, Luas daun, Luas Daun, Kadar Klorofil dan media yang terbaik dalam mendukung pertumbuhan tanaman adalah media arang sekam. Indranada(1989) dalam (Andriana et al., 2013) menyatakan salah satu cara untuk memperbaiki media tanam yang mempunyai drainase buruk adalah dengan menambah arang sekam pada media tanam

Menurut (Mas'ud, 2009) Nutrisi dan Media tanam berbeda memberikan hasil yang berbeda terhadap pertumbuhan dan hasil tanaman selada.

Untuk lebih jelas pengaruh pupuk organic cair dan media tumbuh terhadap produksi bersih pertanaman dapat dilihat pada gambar 4 .

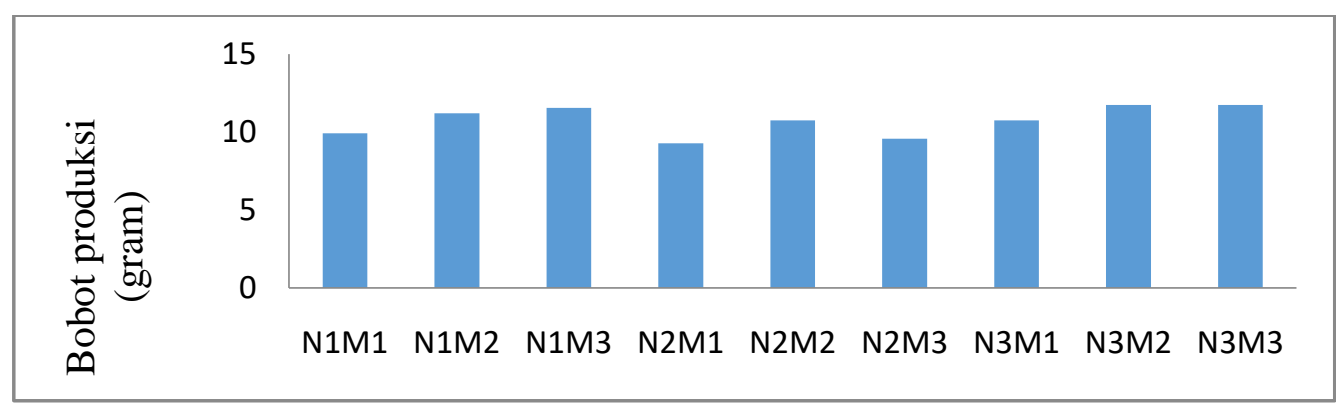

Gambar 4. Histogram Interaksi Konsentrasi Pupuk Organik Cair dan Media Tanam terhadap Bobot Produksi.

\section{KESIMPULAN DAN SARAN}

\section{Kesimpulan}

Perlakuan konsentrasi pupuk organik cair dan media tanam berpengaruh nyata terhadap tinggi tanaman pada umur 28 HST namun tidak berpengaruh nyata terhadap jumlah daun, bobot segar tanaman , berat akar dan bobot produksi. Perlakuan (N2M1) menunjukkan tinggi tanaman tertinggi pada umur 14 dan 21 HST masing-masing $(16,50 \mathrm{~cm}),(23,54 \mathrm{~cm})$, pada umur 28 HST terdapat pada perlakuan N3M2 $(29,04 \mathrm{~cm})$. Jumlah daun umur 14 HST tertinggi terdapat pada perlakuan N1M1 dan N3M1 yang menunjukkan rata-rata yang sama $(6,58)$, umur 21 HST pada perlakuan N2M2 $(8,08)$ dan 28 HST pada perlakuan N3M1 dan N3M2 yang menunjukkan ratarata yang sama $(9,58)$. Bobot segar tanaman tertinggi pada perlakuan N3M3 $(15,29$ gr). Berat 
akar tertinggi terdapat pada perlakuan N3M3 (3,55 gr). Bobot produksi tertinggi terdapat pada perlakuan N3M2 dan N3M3 yang menunjukkan rata-rata yang sama (11,75 gr).

\section{Saran}

Untuk membudidayakan tanaman kailan secara hidroponik agar menggunakan pupuk organic cair $15 \mathrm{ml} /$ liter air dan media cocopit dan arang sekam

\section{E. DAFTAR PUSTAKA}

A.Wahyuningsih, Anis, Sisca Fajriani, N. A. (2016). KOMPOSISI NUTRISI DAN MEDIA TANAM TERHADAP PERTUMBUHAN DAN HASIL TANAMAN PAKCOY (Brassica rapa L .) SISTEM HIDROPONIK THE NUTRITION AND GROWTH MEDIA COMPOSITION ON THE GROWTH AND YIELD OF PAKCOY (Brassica rapa L .) USING HYDROPONICS SYSTEM. 4(8), 595-601.

Agustina, R. (2019). Pengaruh Komposisi Media Dan Nutrisi Hidroponik Terhadap Pertumbuhan Dan Hasil Selada Hijau (. 1(M).

Andhika, R., \& Sugiono, D. (2017). Karakteristik Agronomis Tanaman Kailan (Brassica oleraceae L. var. acephala DC.) Kultivar Full White 921 Akibat Jenis Media Tanam Organik dan Nilai EC (Electrical Conductivity) pada Hidroponik Sistem Wick.2(1), 25-33.

Andriana, H. K., Izzati, M., Saptiningsih, E., Kusuma, A. H., Izzati, M., Saptiningsih, E., Biologi, L., Tumbuhan, F., Biologi, J., Sains, F., \& Diponegoro, U. (2013). Pengaruh Penambahan Arang dan Abu Sekam dengan Proporsi yang Berbeda terhadap Permeabilitas dan Porositas Tanah Liat serta Pertumbuhan Kacang Hijau (Vigna radiata L ). 21(1), 1-9.

Annisava, A. R. (2013). Optimalisasi pertumbuhan dan kandungan vitamin C kailan ( Brassica alboglabra L .) menggunakan bokashi dan ekstrak tanaman terfermentasi. 3(2), 1-10. https://doi.org/10.24014/ja.v3i2.82

Dede Haryadi, Husna Yetti, S. Y. (2015). Pengaruh pemberian beberapa jenis pupuk terhadap pertumbuhan dan produksi tanaman kailan(Brassica alboglaba L). Jom Fapert, 2(2).

Fiona, F. (2010). Pemanfaatan Arang Sekam untuk Memperbaiki Pertumbuhan Semai Jabon ( Anthocephalus cadamba ( Roxb .) Miq ) pada Media Subsoil. Silvikultur Tropika, 01, 24-28.

Iskandar, A. (2016). Pengaruh Dosis dan Macam Larutan Hara terhadap pertumbuhan dan produksi tanaman kailan (Brassica oleraceae) dengan sisitim hidroponik EBB and Flow.

Knaofmone, A. (2016). Pengaruh Konsentrasi dan Dosis Pupuk Organik Cair Terhadap Pertumbuhan Bibit Sengon Laut ( Paraserianthes falcataria , L .). 1(2477), 90-92.

Mas'ud, H. (2009). Sistem hidroponik dengan nutrisi dan media tanam berbeda terhadap pertumbuhan dan hasil selada. Media Litbang Sulteng, 2(2), 131-136.

Perwtasari, B., Tripatmasari, M., \& Wasonowati, C. (2012). AGROVIGOR VOLUME 5 NO . 1 MARET 2012 ISSN 19795777 PENGARUH MEDIA TANAM DAN NUTRISI TERHADAP PERTUMBUHAN DAN HASIL TANAMAN PAKCHOI ( Brassica juncea L .) DENGAN SISTEM HIDROPONIK 1 . Alumni Jurusan Agroekoteknologi , 2 . Dosen Jurusan Agroekoteknologi FP UTM. 5(1), 14-25.

Roidah, I. S. (2014). PEMANFAATAN LAHAN DENGAN MENGGUNAKAN SISTEM HIDROPONIK. Jurnal Universitas Tulung Agung Boborowo, 1(2), 43-50.

Samadi, B. (2017). Teknik Budidaya Sawi dan Pak Choy (First Edit). Pustaka Mina.

Sidiq Fadhil, S. (2019). Pemberdayaan Masyarakat Melalui Hidroponik Sayuran Sederhana Gampong Bujok Teungoh Langsa Barat. 1(2), 117-123.

Sopandie, D. (2014). Fisiologi Adaptasi Tanaman Terhadap Cekaman Abiotik pada Agroekosistem Tropika (N. Januarini (ed.); First Edit). IPB Press.

Wahyu, B., Ika, R., \& Putra, H. (2019). PEMBUATAN PUPUK ORGANIK CAIR DARI LIMBAH BUAH DENGAN PENAMBAHAN BIOAKTIVATOR EM4 Bangun Wahyu R I H P dan Rhenny R. Sains Dan Tehnologi, 11(261), 44-56. 